\title{
Anti-IgE schützt Erdnussallergiker
}

\author{
Bei Erdnussallergien kann schon nach dem Verzehr von \\ weniger als einer Erdnuss zu Übelkeit, Erbrechen und Diarrhöe \\ kommen, in schweren Fällen zu Hypotonie, Bewusstseins- \\ verlust und Tod. Häufig sind Reaktionen durch Nahrungs- \\ mittel, denen die Erdnussbeimengung nicht anzusehen ist. \\ Eine Anti-lgE-Antikörpertherapie kann schützen.
}

$\mathrm{D}$ er in Erprobung befindliche AntiIgE-Antikörper TNX-901 ist ein humanisierter, monoklonaler IgG1-Antikörper, dessen Hauptwirkmechanismus in einer Blockade von Epitopen der $\mathrm{CH} 3-$ Region von IgE besteht. Dadurch wird das Andocken von IgE an den FcєRezeptor von Mastzellen und Basophilen unterbunden und die allergische Kaskade frühzeitig abgebrochen. In einer Dosistitrationsstudie wurden $84 \mathrm{~Pa}$ tienten mit einer im doppelblinden oralen Provokationstest verifizierten Erdnussallergie randomisiert und doppelblind vier Studienarmen zugewiesen: Sie erhielten entweder viermal alle 4 Wochen TNX-901 in den Dosierungen 150 $\mathrm{mg}, 300 \mathrm{mg}$ oder $450 \mathrm{mg}$ beziehungsweise subkutane Plazeboinjektionen.

Die Schwelle für eine allergische Reaktion lag zu Beginn der Studie je nach Patient zwischen $178 \mathrm{mg}$ bis $436 \mathrm{mg}$ Erdnussmehl. Zwischen 2 und 4 Wochen nach Abschluss der Medikation stieg der Provokationsgrenzwert in der Plazebogruppe im Mittel auf $710 \mathrm{mg}$, in der 150-mgGruppe auf $913 \mathrm{mg}$, in der 300-mg-Gruppe auf $1.650 \mathrm{mg}$ und in der 450-mg-Gruppe auf $2.627 \mathrm{mg}$ Erdnussmehl. Der Unterschied zwischen Plazebo und der höchsten verabreichten TNX-901-Dosis ist mit $\mathrm{p}<0,001$ statistisch signifikant. Die systemische und lokale Verträglichkeit war in allen Gruppen vergleichbar.

Fazit: Der monoklonale Antikörper TNX-901 kann vor den Symptomen einer Erdnussallergie vor allem bei unbe-

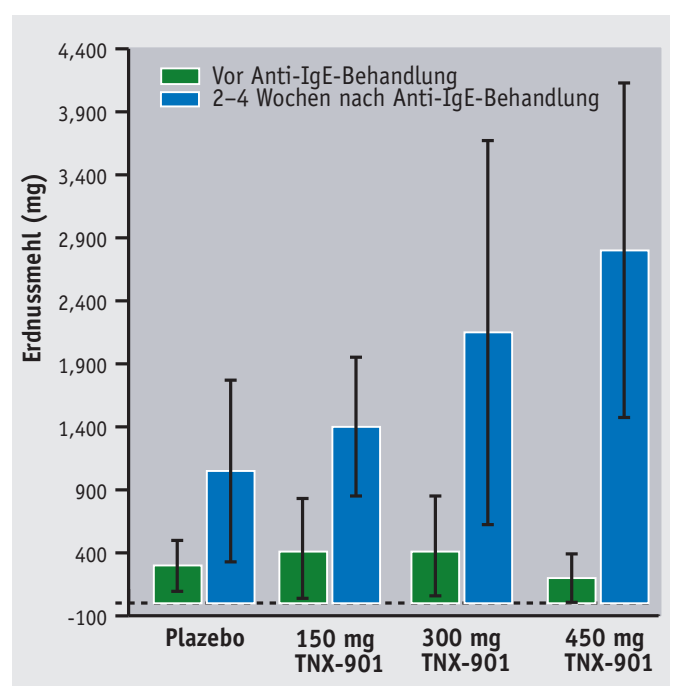

Mittlere erforderliche Dosis an Erdnussmehl, um eine allergische Reaktion zu provozieren. Dargestellt sind die Werte vor und nach Anti-IgEBehandlung. merkter Zufuhr geringerer Mengen an Erdnüssen schützen. In 4-wöchigen Abständen viermal in einer Dosierung von 450 mg gegeben erhöht sich die Provokationsschwelle von einer halben Erdnuss auf immerhin neun Erdnüsse. $b k$

Leung DYM et al. Effect of anti-lgE therapy in patients with peanut allergy. N Engl J Med 2003; 348: 986-93

\section{Gezuckerte Proteine - für Allergiker bitter}

\section{Viele Proteine sind glykosyliert, d. h. mit Kohlenhydratketten auf ihrer Oberfläche versehen. Bisher war unklar, ob diese Seitenketten allergen wirken. Wenn ja, könnte das wichtige Konsequenzen für Diagnostik und Therapie haben.}

\footnotetext{
_ ine deutsch-österreichische Arbeits- gruppe legte jetzt eine gut kontrollierte In-vitro Studie über die Aktivität von Kohlenhydraten (KH) der $\beta$-Fructofuranosidase (Lyc e 2), eines Allergens aus Tomaten, vor. Die elegante Methode besteht in der Mischung von IgEfreien Basophilen mit Patientenserum und verschiedenen Allergenen. Im Serum enthaltenes IgE besetzt dann die zellulären Rezeptoren. Wenn IgE vorhanden ist, das die zugemischten Allergene erkennt, führt das zur Freisetzung von Histamin, das über ELISA detek-
}

tierbar ist. Die untersuchten Seren stammten von zwölf Patienten mit Tomatenallergie.

Bei vier Seren provozierte aus Tomaten aufgereinigtes Lyc e 2 eine starke Antwort der Basophilen, die ungefähr der Antwort mit Gesamt-Tomatenextrakt entsprach. Dagegen war rekombinantes rLyc e 2 in diesen Fällen inaktiv. Das rekombinante Protein wird in Bakterien produziert und ist daher nicht glykosyliert - ein deutlicher Hinweis, dass die KH-Seitenketten von Lyc e 2 die relevanten Epitope enthalten. Ein weiterer Beweis für die Aktivität der $\mathrm{KH}$-Seitenketten war ein künstlich mit den Seitenketten von Lyc e 2 glykosyliertes Protein. Dieses Protein war ebenfalls aktiv, aber nur, wenn die Seitenketten vorhanden waren.

Bei den Seren der restlichen acht Probanden lag keine Reaktivität auf $\mathrm{KH}-$ Seitenketten vor, hier sind wohl andere Allergene auslösend.

Fazit: KH-Seitenketten von Proteinen können allergisch relevante Epitope enthalten. Die hohe Kreuzreaktivität dieser Seitenketten muss berücksichtigt werden, wenn mit Allergenextrakten diagnostiziert wird.

Foetisch $\mathrm{K}$ et al. Biological activity of IgE specific for cross-reactive carbohydrate determinants. J Allergy Clin Immunol 2003; 111: 889-96 